\title{
Mode I stress intensity factors of sickle-shaped surface cracks in round solid bars under bending moment
}

\author{
Al Emran Ismail \\ Faculty of Mechanical and Manufacturing Engineering \\ Universiti Tun Hussein Onn Malaysia, 86400 Batu Pahat, Johor, Malaysia \\ Email: emran@uthm.edu.my / al_emran@hotmail.com \\ Phone: +6074537675; Fax: +6074536080
}

\begin{abstract}
Sickle-shaped crack may occur on the surface of solid round cylinder under some specific reasons such as design discontinuities or material defects. This type of crack is capable to grow circumferentially around the bar and it is called a sickle-shaped surface cracks. The complete solution of stress intensity factors (SIF) of sickle-shaped surface cracks is hard to find and therefore the objective of this paper is to present the behaviour of these cracks under remotely applied bending moment. In order to understand the role of these cracks, there are seven crack aspect ratios, $a / b$ considered, ranging from 0.0 to 1.2. For each crack aspect ratio, there are six relative crack depths, $a / D$ used ranging from 0.1 to 0.6. ANSYS finite element program is used to model the crack. Stress intensity factor (SIF) which is based on the $J$-integral is used to characterize the cracks. For relatively shallow cracks $(a / D \leq 0.3)$, the role of SIFs along the crack front is insignificant regardless of $a / b$. However, for the deeper cracks $(a / D>0.3)$, the effect of $a / b$ is tremendous on the SIFs. If $a / b$ is increased from 0.0 to 1.2 , higher SIFs are obtained around the central compared with the outer regions of the crack fronts. This is due to the fact that the circumferential cracks at both sides of the bar experience lack of mode I opening mechanism compared with the crack faces at the upper side cracks. It is suggested that the phenomena of crack closure are not only caused by the plastic deformation, surface roughness and other related factors but the shape of crack also plays an important role.
\end{abstract}

Keywords: Sickle-Shaped Crack; Surface Cracks; Round Solid Bars; Bending Moment.

\section{INTRODUCTION}

Crack is one of the biggest problems in all engineering fields leading to premature failures. There are several factors affecting the formation of cracks, for example material defects [1] and mechanical discontinuities [2-12]. There are tremendous numbers of work focused on such cracks [13-16]. Toribio, Matos [13] studied the effect of crack aspect ratio changes with the relative crack depth by considering the ParisErdogan law. It is found that for crack depth between 0.7 to 0.8 diameter, the crack shape evolution is slightly increasing for free sample ends and decreasing for constrained ends. Śnieżek, Ślęzak [14] experimentally investigated the propagation of semi-elliptical surface cracks of austenitic steel. For rectangular-shaped samples, it is confirmed that fatigue crack propagation takes the shapes of semi-ellipse before the final failure occurs. Coules [15] also successfully used semi-elliptical shaped surface cracks in analyzing the interaction between two dissimilar surface cracks. Surface 
interactions are then critically assessed and found to be satisfactory for cracks loaded in uniform tension. Weißgraeber, Felger [16] studied the crack at elliptical holes considering the stress intensity factor and finite fracture mechanics solution. An improved stress intensity factor for cracks emanating from these holes is proposed where this solution yielded very good results for a wide range of parameters.

A recent review of the crack propagations of metal can be found in [17-22]. It suggested the small crack as a damage tolerant design criterion before the crack propagates. Based on the recent literature found in [13-17, 23-25], none of those discussed on the sickle-shapes are assumed as crack geometries. The solution of sickleshaped surface crack is hard to find, as it usually occurs for the case of bolt where the crack forms circumferentially around the solid bar. Currently, most of the cracks are assumed to take a semi-elliptical shape even though the cracks are subjected to pure torsion [26]. The fractographic observation can be found in [11]. It indicated the crack was formed around the bolt and propagated into the bar. Once the crack driving force approached the critical value, the bolt experienced the final failure. The finite element analysis on the sickle-shaped crack was documented by Mattheck, Morawietz [11]. However, due to the computational disadvantages, the SIFs of such cracks were limited. Based on the comparison between the normalized SIFs among other works, there are huge discrepancies between the results. Then, Hobbs, Burguete [12] experimentally conducted using a photoelastic approach on the sickle-shaped cracks. They have concluded that the shape of the crack front does not have a significant effect on the SIFs especially the maximum SIF at the middle of the crack front. However, it does influence the distribution around the crack front. Carpinteri and Vantadori [10] investigated the SIFs of sickle-shaped cracks subjected to complex mode I loading. On the other hand, Carpinteri, Brighenti [27] extended their work to study the sickle-shaped crack under eccentric axial loading. The SIFs obtained from [28], were not well documented where it is hard to find the complete SIFs across the crack front. The SIFs for semi-ellipticalshaped surface cracks can be found in [8, 29, 30] under modes I, II and III. Therefore, the purpose of this paper is to present and analyze the stress intensity factors (SIFs) along the crack front for the sickle-shaped surface crack in round bars. There are two important parameters to be investigated on their effects on the SIFs such as crack aspect ratio, $a / b$ and the relative crack depth, $a / D$. The crack aspect ratios used are in the range of 0.0 to 1.2 with an increment of 0.2 . Whereas for each $a / b$, there are six $a / D$, namely $0.1,0.2,0.3,0.4,0.5$ and 0.6. ANSYS finite element program is used to model and analyze the crack and the SIFs for each crack condition is discussed in terms of $a / b$ and $a / D$.

\section{METHODS AND MATERIALS}

\section{Stress Intensity Factors Based On J-Integral}

It was firstly introduced by Rice [23] by assuming a crack in two-dimensional plate, $J$ integral is defined as a contour, $\Gamma$ around the crack tip. It is evaluated counter-clockwise as depicted in Figure 1 and can be expressed as Eq. (1) [31]:

$$
J=\int_{\Gamma}\left(W d y-\vec{T} \cdot \frac{\partial u}{\partial z} d s\right)
$$

where, $\vec{T}$ is an outward traction vector along the contour, $\Gamma$ is defined as $T_{i}=\sigma_{i j} n_{i}$ or it is a force per unit length, $u$ is a displacement vector and $d s$ is an element on the contour, $\Gamma$. 
While, $W$ is a strain energy density expressed as Eq. (2):

$$
W=\int_{0}^{\varepsilon} \sigma_{i j} d \varepsilon_{i j}=\int_{0}^{\varepsilon}\{\sigma\}^{T} d\{\varepsilon\}
$$

where, $\varepsilon_{i j}$ is a strain tensor and $\{\varepsilon\}$ represents a strain vector. In elastic-plastic analysis $J$-integral is composed from two parts, elastic $J$-integral, $J_{e}$ and plastic $J$-integral, $J_{p}$ as [14] in Eq. (3):

$$
J=J_{e}+J_{p}
$$

where, $J_{e}$ can be obtained numerically using finite element analysis (FEA) or by the Eq. (4) $[15]$ :

$$
J_{e}=\frac{K_{I}^{2}}{\kappa}
$$

where, $K_{I}$ is the mode I elastic SIF, $\kappa=E$ for plane stress and $\kappa=E /\left(1-v^{2}\right)$ for plane strain. Since this work only concerns the elastic analysis, the plastic term is omitted from Eq. (3).

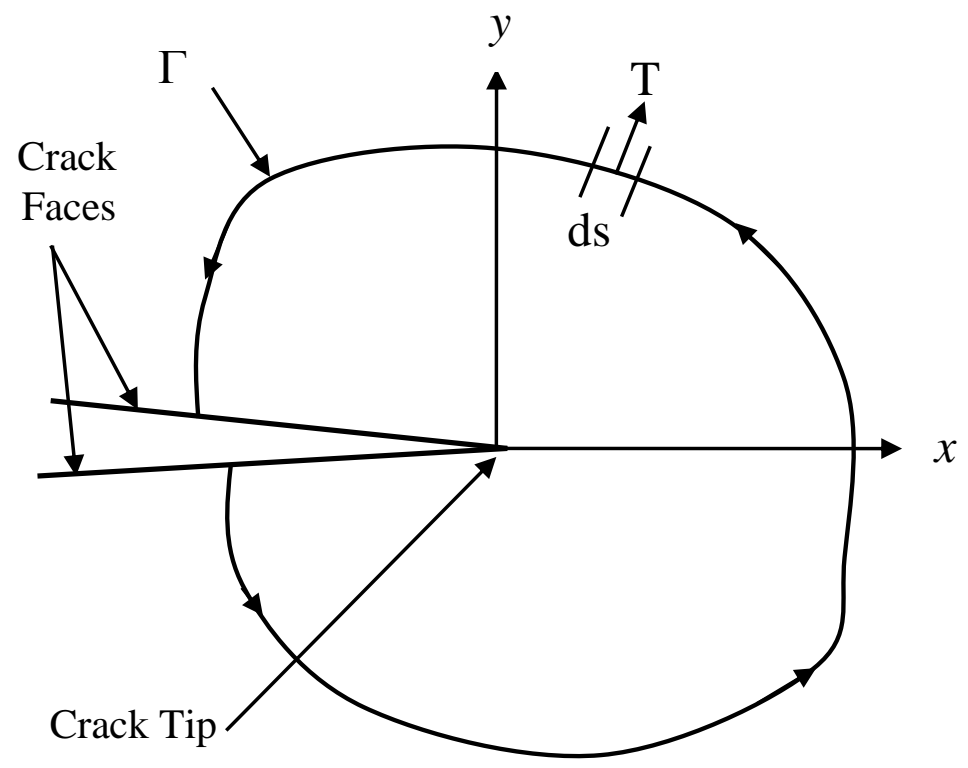

Figure 1. A definition of contour path to evaluate J-integral [31].

J-integral is computed through the virtual crack extension (VCE) method which is also called as domain integral method [32]. In order to determine the J-integral, proper selection of contour path is important even though $\mathrm{J}$-integral analysis is a path independent method. This is because large material shrinkage occurs around the crack tip [31]. In this work, $5^{\text {th }}$ contour which gives $0.05 \%$ compared with $4^{\text {th }}$ contour is selected, showing a path independent effect around the crack tip. All the calculations in determining the fracture parameters are conducted automatically through the use of ANSYS parametric design language (APDL). 


\section{Sickle-Shaped Surface Cracks}

Due to the symmetrical effect only a quarter finite element model is used where the radius, $R=25 \mathrm{~mm}$ and the half length of the solid round bar is $200 \mathrm{~mm}$. Figure 2 shows the cross-sectional area of sickle-shaped surface crack where $O$ and $O$ ' are the central point of circle and semi-ellipse, respectively. There are seven values of crack aspect or semi-elliptical ratios, $a_{\text {minor }} / b_{\text {major }}$ are used ranging 0.0 to 1.2 with an increment of 0.2 . While, six relative crack depths, $a / D$ are used, namely $0.1,0.2,0.3,0.4,0.5$ and 0.6 . All of these are used in order to study the influence of different relative crack depths and crack aspect ratios on the stress intensity factors. The SIFs are determined at six different locations along the crack front and the SIF at point $C$ is not determined due to the singular problem. It is estimated that the nearest point to point $C$ is $83 \%$ measured from point $A$. The location of each point along the crack front is also normalized such as $x / h$ for the location of point $P$.

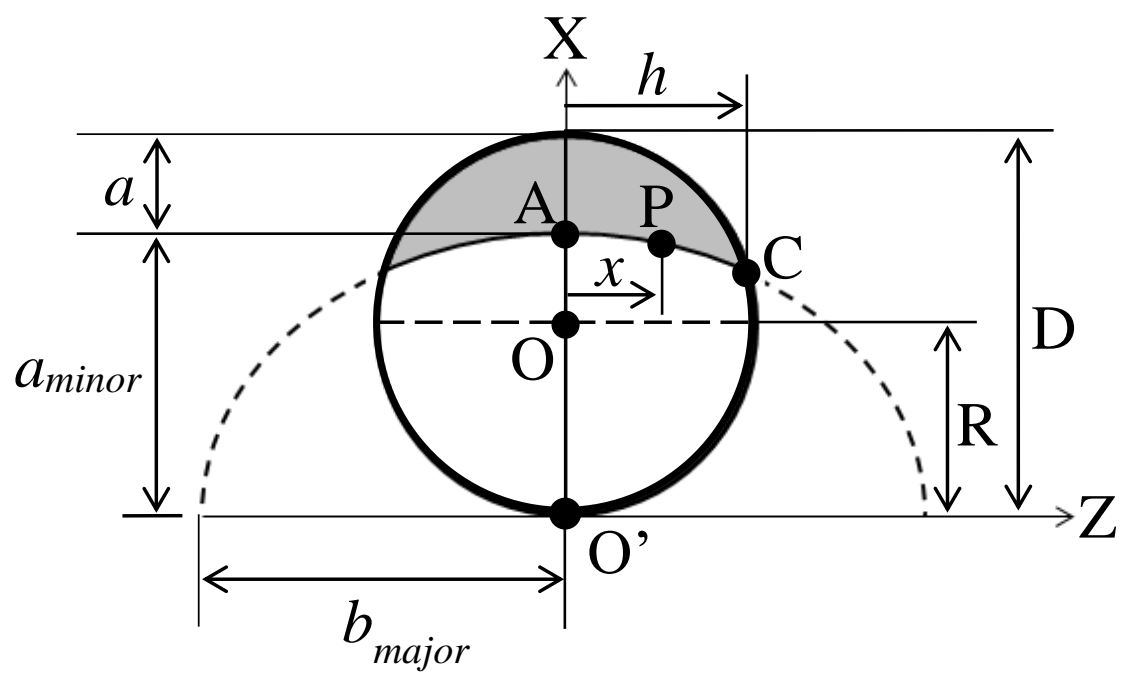

Figure 2. Nomenclature of sickle-shaped crack.

\section{Finite Element Modelling}

The construction of finite element model is started with the model of cross-sectional area as shown in Figure 3. Once it is completed, the model is extruded along the $y$-axis with a length of $200 \mathrm{~mm}$. The extruded volume model is presented in Figure 3(a). Special attention is given at the tip of the sickle-shaped crack where iso-parametric element is used. The square-root singularity of stresses and strains around the crack tip is modelled by shifting the mid-point nodes to the quarter-point location close to the tip. Firstly, the two-dimensional model is meshed and then it is swept along the crack front. Then, the remaining model is meshed with irregular similar elements. The quarter finite element model is shown in Figure 3(b) with its corresponding crack tip singular element as in Figure 3(c). In order to remotely apply the bending moment to the model, an independent node is created about $50 \mathrm{~mm}$ ahead of bar ends where it is modelled with target element while the element at the edge of the bar is modelled with contact element. Then, it is required that the whole solid round bar to follow any mechanical movement by the independent node. Then, both the independent node and the nodes at the surface edge of the bar are connected using rigid element as shown in Figure 3. Then, the following-type element is used in order to ensure any mechanical displacements that occur at the pilot node to be followed by the solid round bar. On the other hand, the whole edge surface is symmetrically constrained except the crack faces. The left surface 
plane is also symmetrically constrained. The bending moment is applied to the independent node.

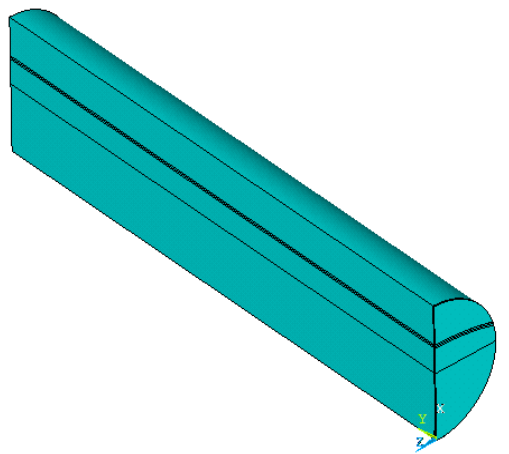

(a)

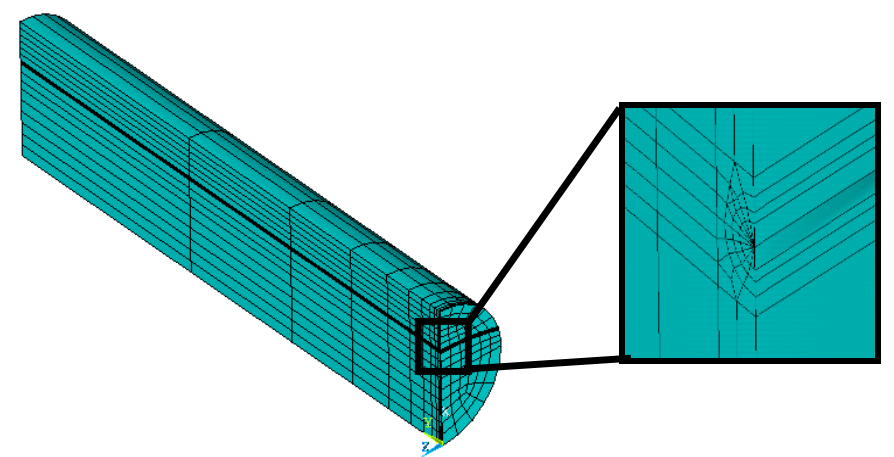

(b)

(c)

Figure 3. (a) An extruded volume cracked model, (b) Quarter finite element model and (c) Corresponding singular element around the crack tip.

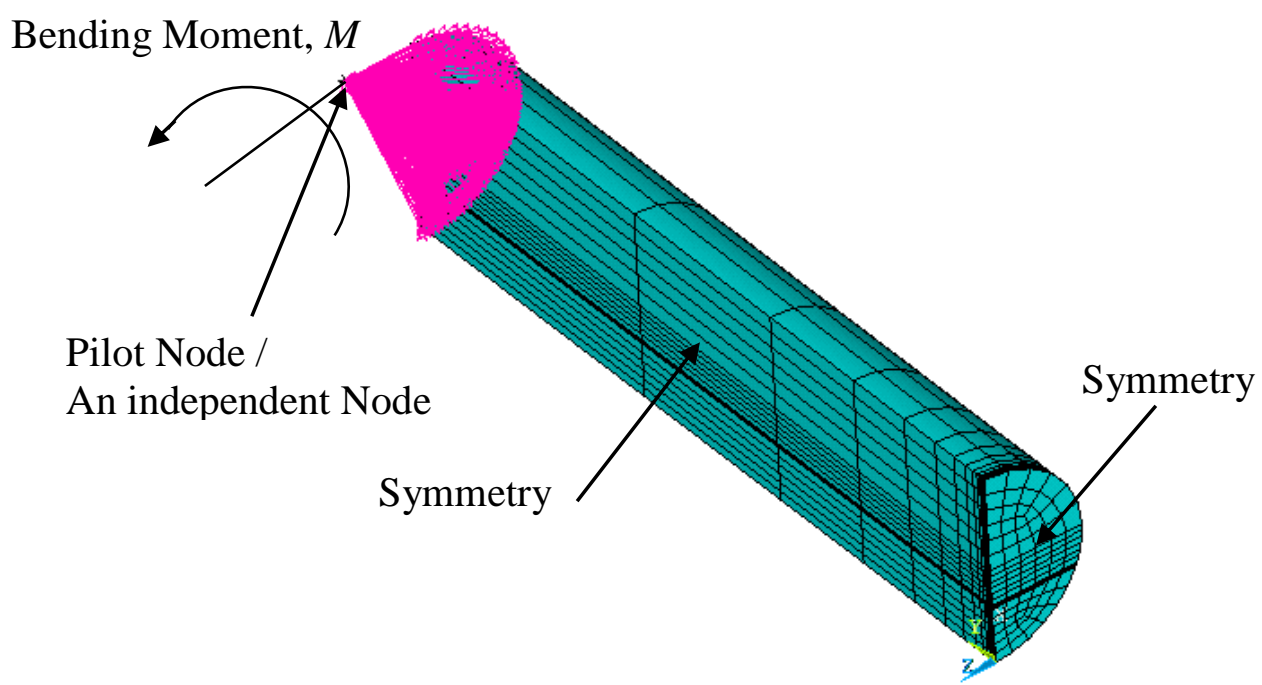

Figure 4. The boundary conditions and the loading on the finite element model.

The stress intensity factors along the sickle-shape crack front are determined using ANSYS finite element program. The determination of SIFs is based on the Jintegral where it can be directly converted into SIFs using Eq. (5) as long as the problem is within the elastic ranges and has fulfilled the plain strain condition [32, 33]:

$$
K_{I}=\sqrt{\frac{J_{e} E}{1-v^{2}}}
$$

where, $K_{I}$ is a mode I SIF, $J_{e}$ is a J-integral determined directly from program, $E$ is a modulus of elasticity and $v$ is a Poisson's ratio. In order to generalize the SIFs, it is recommended to convert them into a normalized value called a mode I dimensionless SIF or geometrical correction factor, $F_{I}$ as Eq. (6): 


$$
F_{I}=\frac{K_{I}}{\sigma \sqrt{\pi a}}
$$

where, $\sigma$ is an applied stress and $a$ is a crack depth. Before the model is used further, it is compulsory to validate that the present model is in the right condition. According to Figure 5, it is revealed that the present model is well agreed with the existing model. Therefore, this present model can be utilized for the further analysis.

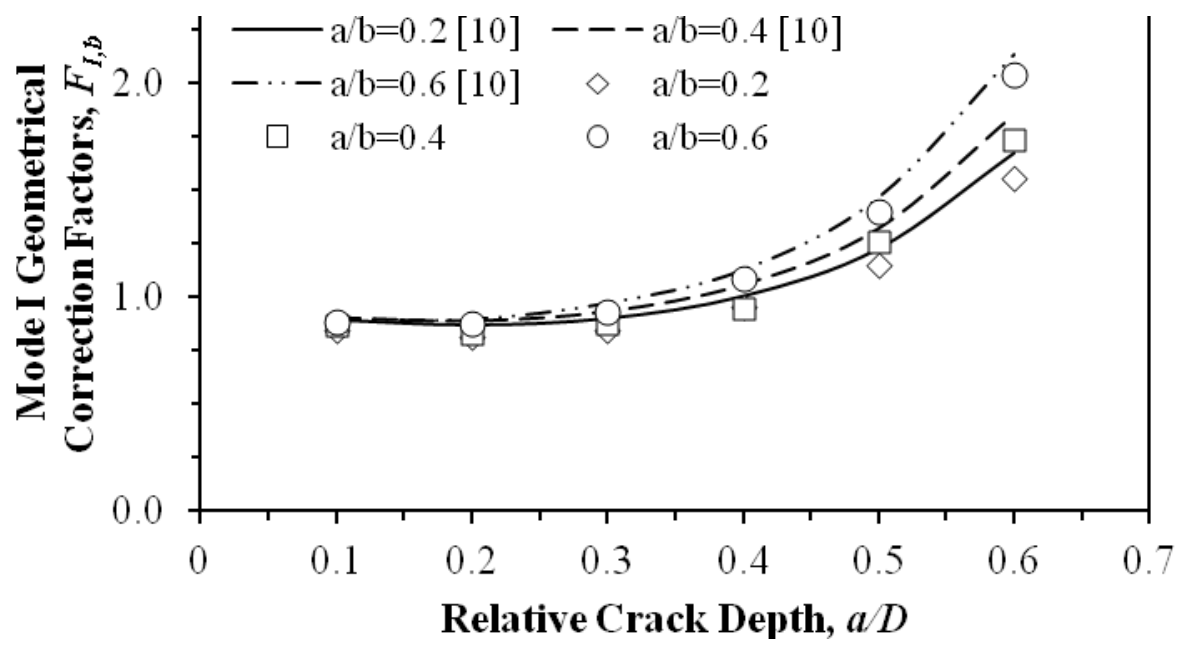

Figure 5. Model validations of the present and the existing models.

\section{RESULTS AND DISCUSSION}

\section{Effect of Crack Aspect Ratios on the SIFs}

Figure 6 presents mode I normalized SIFs or geometrical correction factor, $F_{I, b}$ against the normalized coordinate along the crack front when the relative crack depth, $a / D$ is increased for different crack aspect ratios, $a / b$. It is also revealed that for $a / D \leq 0.3$, the SIFs have no significant difference when $a / D$ is varied since the shapes of crack fronts are almost flattened or straight. Similar results can be found in [9-12] and therefore it can be called as shallow cracks. When $a / D>0.3$, the effect of $a / D$ on the SIFs is tremendous. This behaviour is observed for all crack aspect ratios. Referring to Figure 6 , the patterns are SIFs which can also be categorized according to the ratio of $a / b$. For $a / b \leq 0.2$, the SIFs are almost flattened along crack front, however, the SIFs closer to the outer point are slightly higher than others. This indicates that for straight or almost straight crack front, the crack is probably initiated around those regions [9]. Toribio, Matos [13] and Yang, Kuang [34] revealed that crack aspect ratios play an important role in determining the shape of crack front, however it depend on the type of loading. However, when $a / b>0.2$, most of the SIFs located around the outer points start to decrease when compared with the SIFs closer to the central point. This behaviour is due to the fact that when the crack aspect ratio increases, the cracks appear circumferentially around the solid bar [7-11]. It is difficult for the circumferential cracks to experience mode I opening mechanism and therefore this reduces the SIFs. The effect of SIF reductions is more significant if higher ratio of $a / b$ is implemented. It is also observed 
that for $a / b \geq 0.8$, the SIFs closer to the outer surface are almost similar indicating that the cracks are not fully opened since the cracks are located at the sides of the round bar.

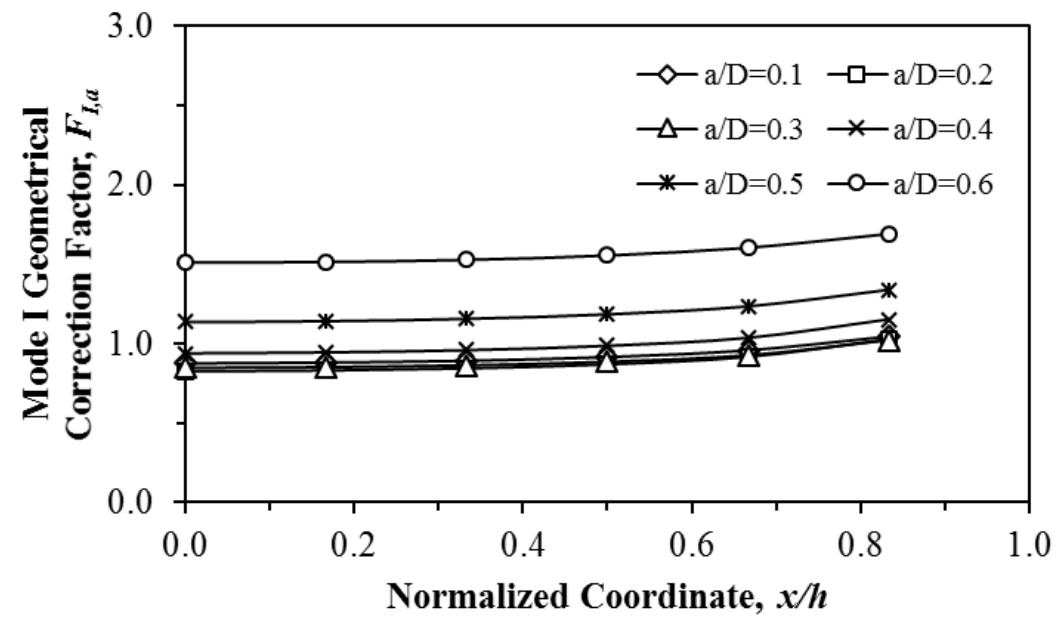

(a)

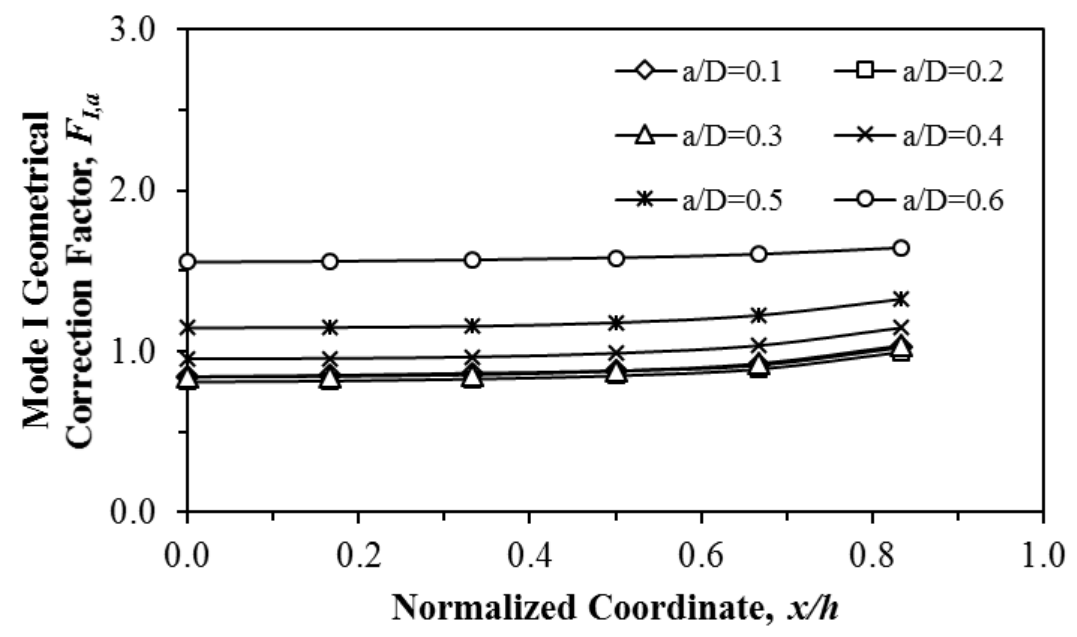

(b)

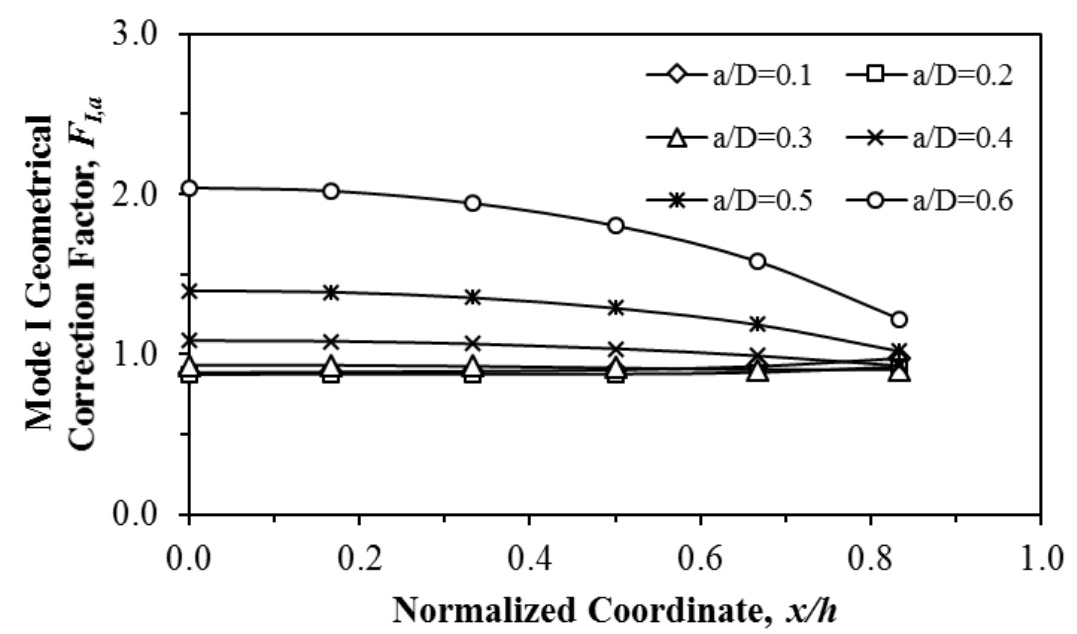

(c)

Figure 6 Continued ... 


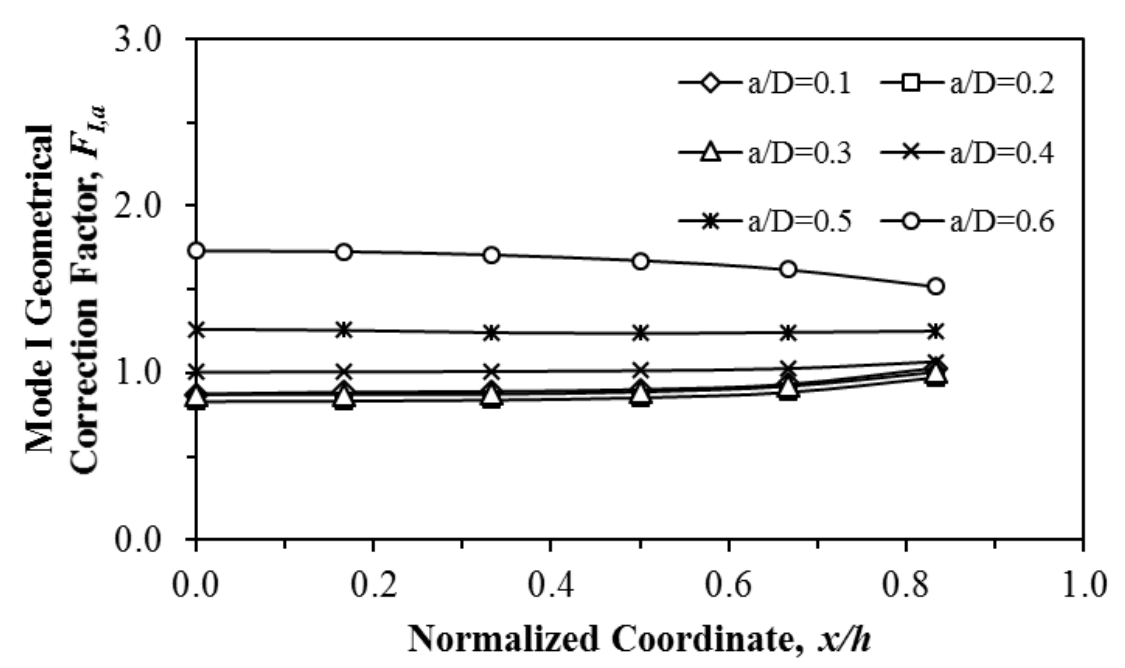

(d)

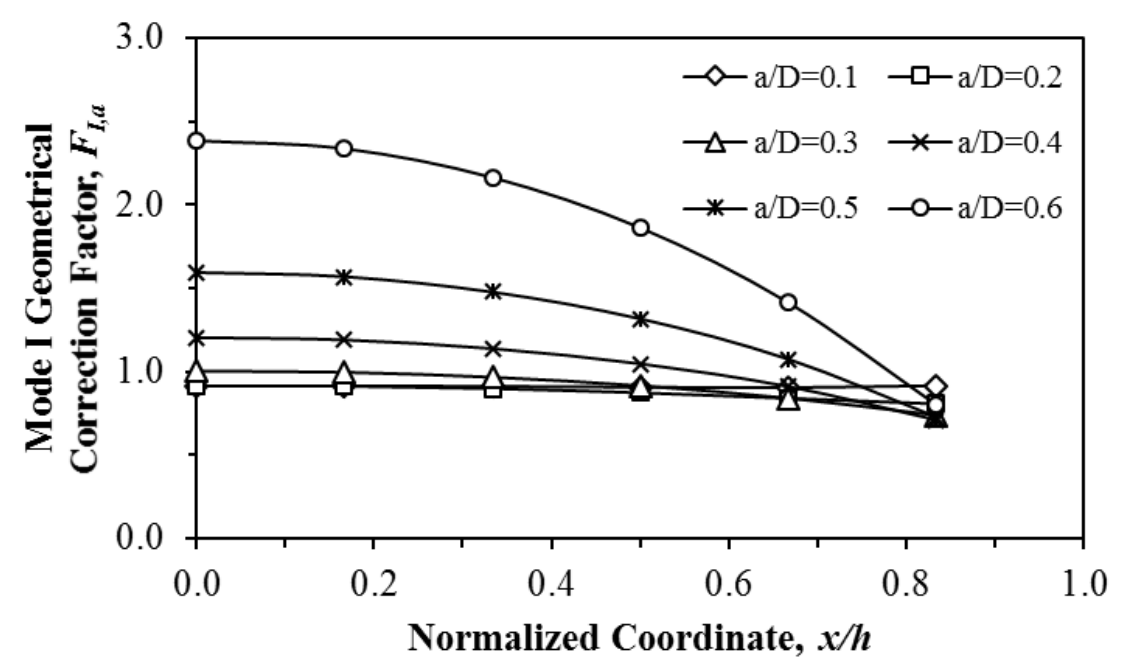

(e)

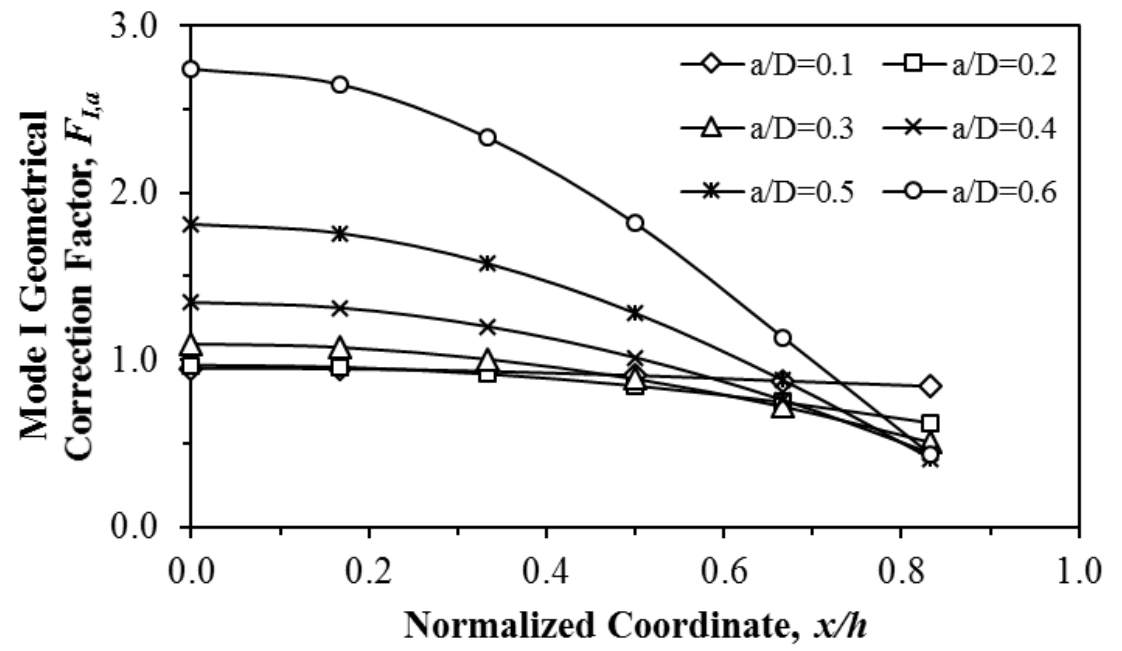

(f)

Figure 6. The effect of $a / D$ on the mode I SIFs along the crack front for difference, $a / b$ (a) 0.0, (b) 0.2 , (c) 0.4 , (d) 0.6 , (e) 0.8 , (f) 1 . 


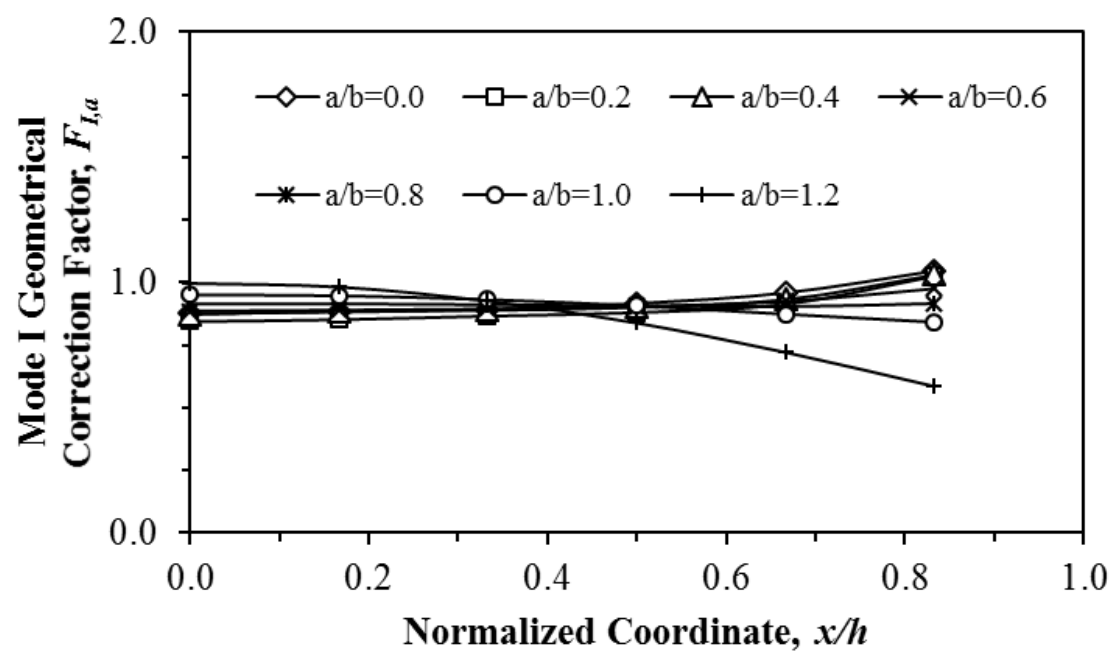

(a)

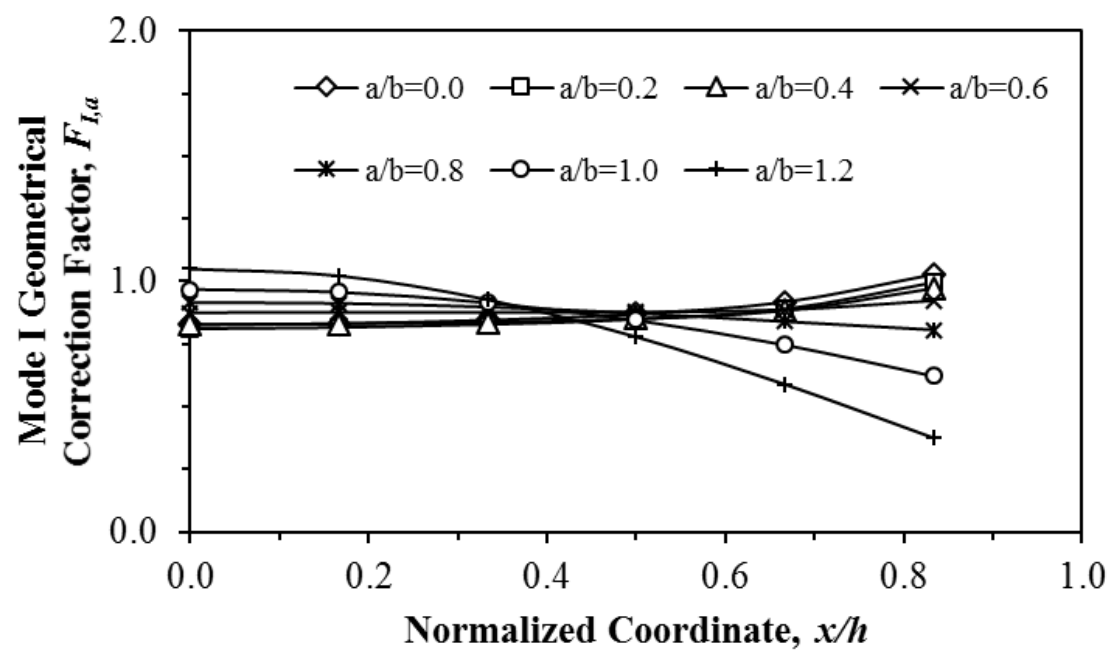

(b)

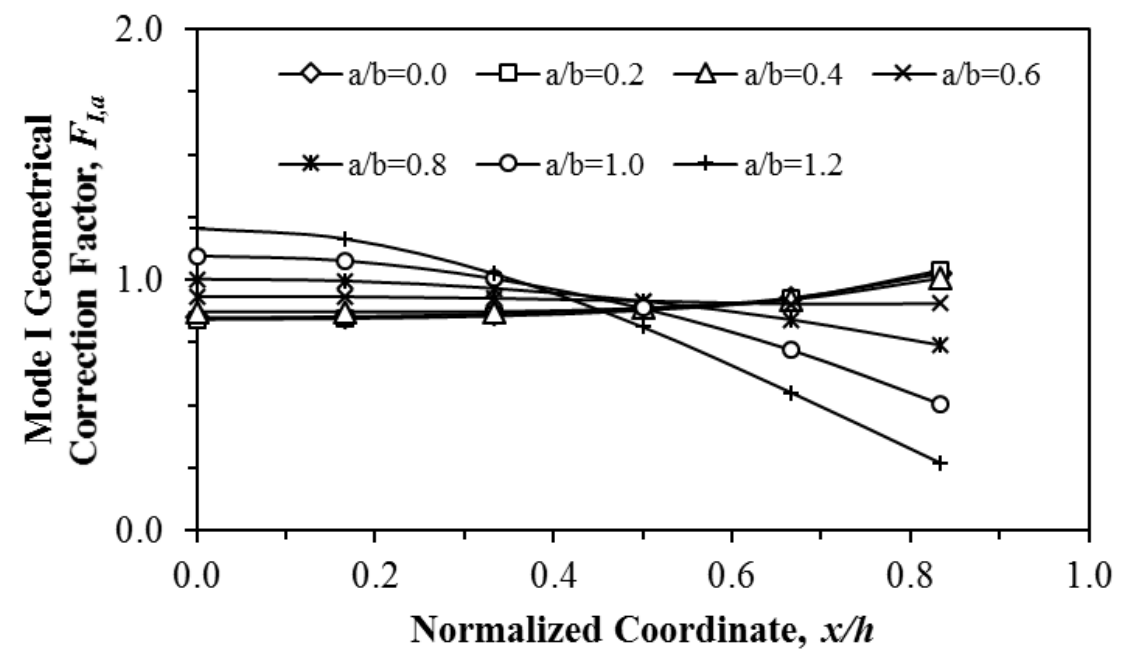

(c)

Figure 7 Continued... 


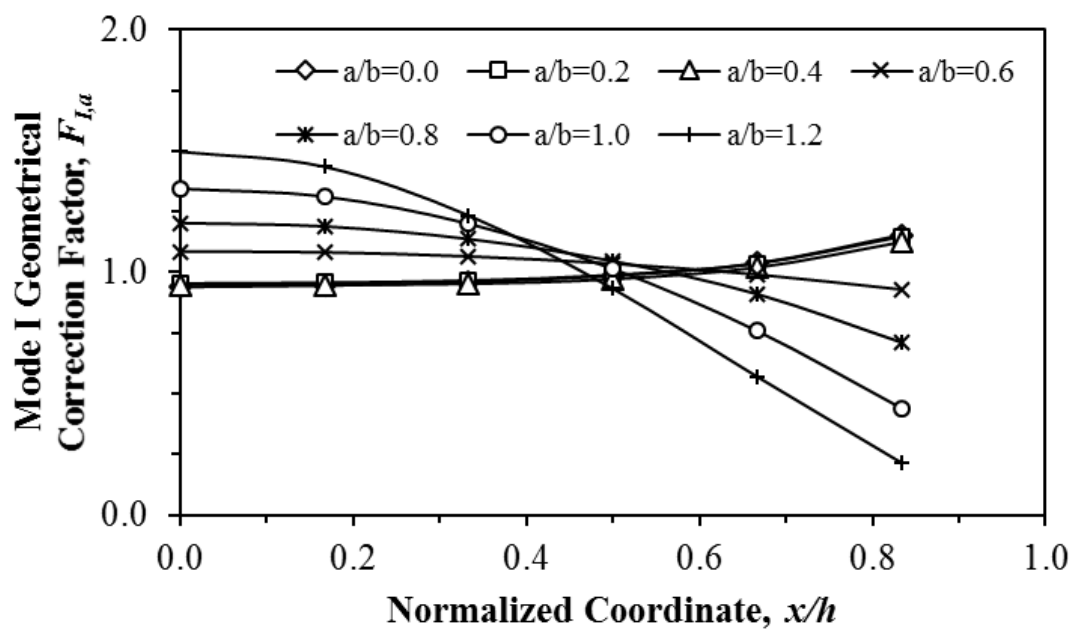

(d)

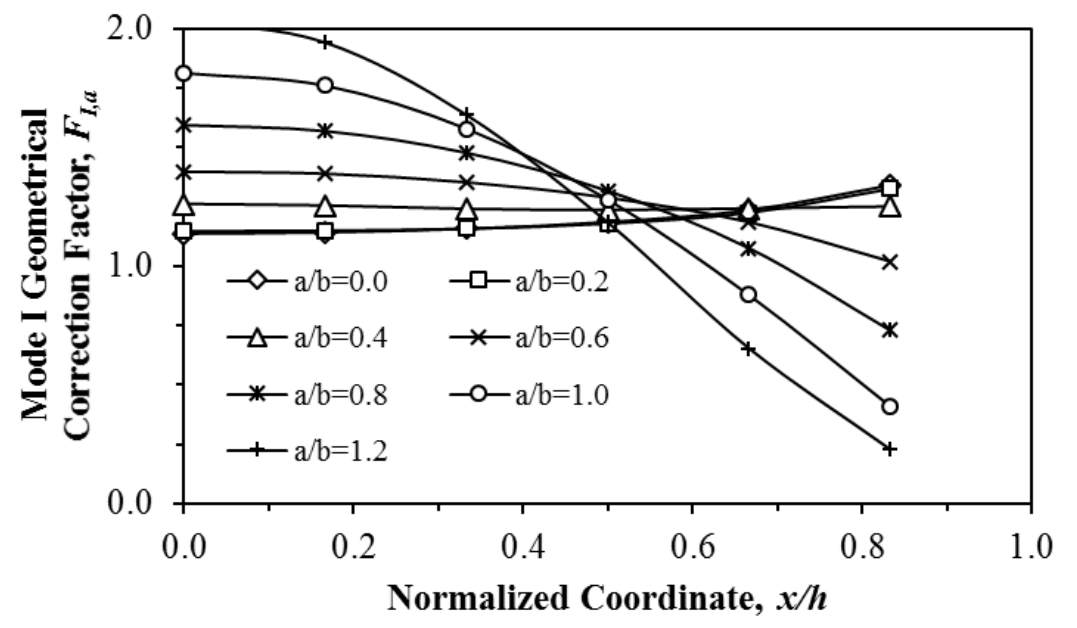

(e)

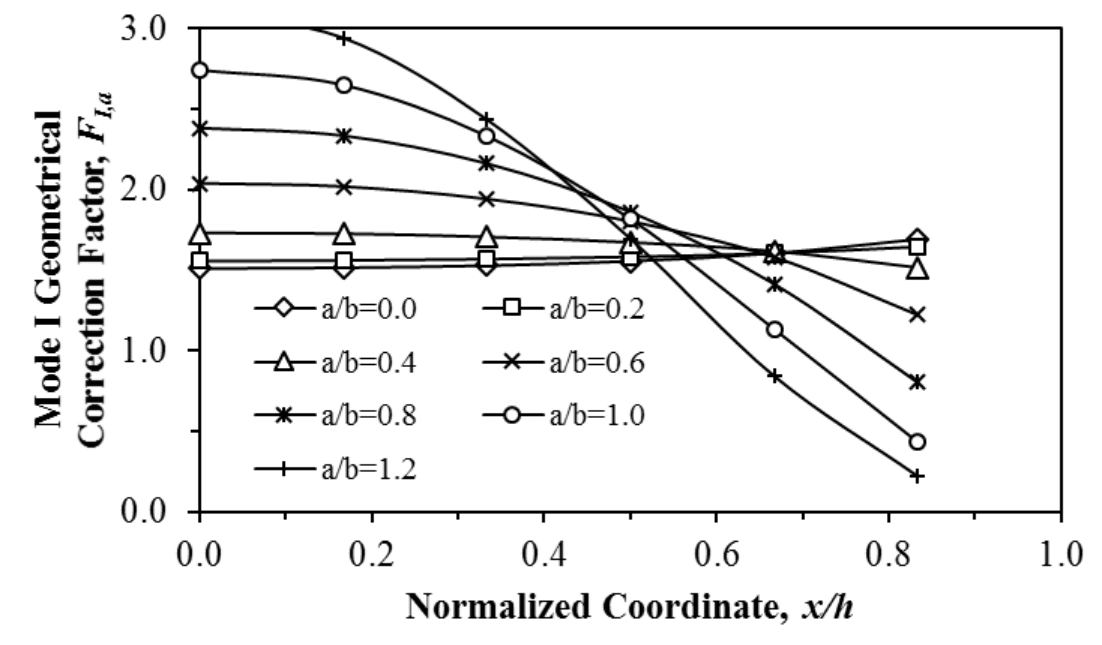

(f)

Figure 7. The effect of $a / D$ on the mode I SIFs along the crack front for difference $a / b$, (a) 0.1 , (b) 0.2 , (c) 0.3 , (d) 0.4 , (e) 0.5 and (f) 0.6 . 


\section{Effect of Relative Crack Depth on the SIFs}

Figure 7 shows the dimensionless mode I SIFs against the normalized coordinates, $x / h$ along the crack front when crack aspect ratios, $a / b$ are increased for different relative crack depths, $a / D$. In general, for relatively shallow cracks $(a / D \leq 0.3)$, the roles of SIF along the crack fronts are insignificant. However, the SIFs are slightly decreased especially around the outer edge when compared with the SIFs around the middle region of the crack front. If $a / D$ is increased, the distributions of SIFs along the crack front are more pronounced where higher SIFs can be obtained within the area closer to the central region. It is clearly observed that there is a transition or turning point between higher and lower values of SIFs and it depends on the $a / D$. For shallow cracks $(a / D \leq 0.3)$, the transition point is $x / h \approx 0.4$. For $0.4 \leq a / D \leq 0.5$, the transition point is $x / h \approx 0.5$ whereas $x / h \approx 0.6$ for $a / b=0.6$. The dependency of transition point of $x / h$ on the $a / b$ indicates that the geometries of the cracks play an important factor in determining the SIFs. For example, a crack with $a / b=1.2$, the crack is formed almost around the round bar. The crack on the upper side experiences higher bending stress while minimum stress occurs at the side cracks. In comparison, if $a / b \leq 0.2$, the cracks are straight-shaped or almost flattened. In this case, the bending stress is distributed uniformly along the crack front thus opening the crack faces in an identical manner. Then, this stress opens the crack faces with a similar angle or displacement. Therefore, the SIFs are almost flattened as shown in Figures 7(a) and 7(b). On the other hand, for $a / b \geq 0.6$, the SIFs before the turning point are higher that the SIFs after such point. However for $a / b<0.6$, the behaviour of SIFs along the crack front is different where the SIFs are higher around the outer edge compared with the region closer to the central point. The role of crack face deformations on the distributions of SIFs is discussed in the third section of the discussion. The detail of SIFs for various crack geometries along the crack fronts are tabulated in Table 1.

\section{Sickle-Shaped Surface Crack Deformations}

The crack shapes strongly affect the distributions of SIFs along the crack front. Figure 8(a) reveals the deformations of crack faces for $a / b=0.0$ and $a / D=0.4$ under bending moment. For better visualization, all models are constructed in threedimensional finite element model. For relatively straight crack $(a / b \leq 0.2)$, the crack has almost uniformly displaced across the crack front. This is suggested to confirm that the SIFs along the crack front are almost flattened as shown in Figures 6(a). Referring to the yellow circle, the crack has opened uniformly without any closure effect. Meanwhile Figure 8(b) shows the crack deformation for $a / b=1.2$ and $a / D=0.4$. There are two circles indicating two regions of opening and closing mechanisms. Red circle indicates the crack experiences an opening mechanism. However, blue circle indicates the region closer to the outer point of the crack front has almost closed. Based on Figure 7(f), the effects of crack geometry on the SIFs are obvious where they can be divided into categories depending on the transition point. This point is actually the boundary between an opening and closing mechanism of the crack faces. The lower values of SIFs are obtained after this point due to the fact that the crack faces experience a closure phenomenon. It occurs in the situation where the crack faces are supposed to open, however the cracks on both sides of bar are closed. Bovsunovsky [35] emphasized the importance of crack closure since it affects the damping characteristics of crack structures. 


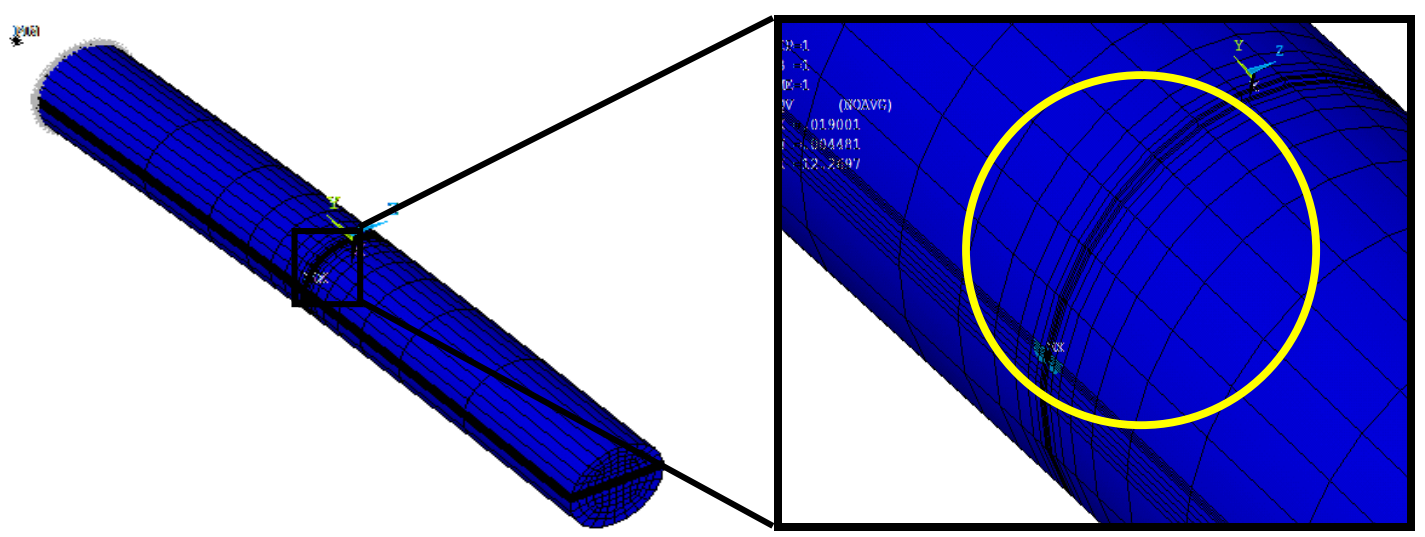

(a)

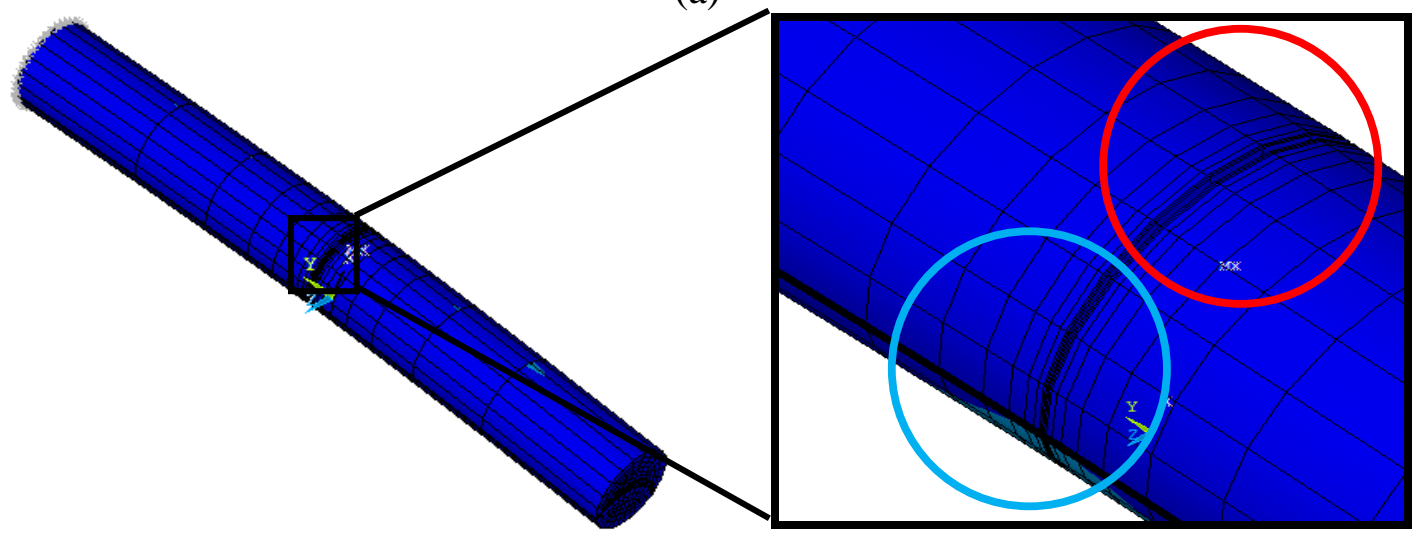

(b)

Figure 8 Crack deformations under bending moment, (a) $a / b=0.0$ and $a / D=0.4$ and (b) $a / b=1.2$ and $a / D=0.4$.

Stress Intensity Factors at the $\boldsymbol{x} / \boldsymbol{h}=\mathbf{0 . 0}$

Figure 8 shows the variation of stress intensity factors at the middle point along the crack front $(x / h=0.0)$ for different $a / b$. These SIFs are also the maximum value compared with other SIFs of identical crack front. In general, higher SIFs are obtained when $a / b$ ratios increase. For the relatively shallow cracks, in this case $a / D \leq 0.2$, the effects of geometries on the SIFs are insignificant where the stress intensity factors are almost identical. Similar works can be found in [10-13] where the stress intensity factors along the crack front for crack geometries of $a / D \leq 0.2$ do not have much difference. However when deeper cracks are used, the role of $a / b$ become of paramount importance. Figure 8 also reveals that when higher $a / b$ is used, the maximum SIFs occur at the middle point along the crack front. It indicates that under bending moment, the crack relatively starts to initiate firstly at the mid-point before going to other locations. For the case of $a / b \leq 0.2$ (straight and almost straight-fronted cracks), the SIFs for $a / D \leq$ 0.4 are relatively flattened. This is to show that the cracks grow along the crack front are almost uniformed where the tendency of the crack to initiate probably is in a similar manner. However when the $a / D \geq 0.5$, different SIFs behaviour is observed, where the SIFs at $x / h=0.0$ are gradually increased. This is due to the fact that when $a / b$ increases, the ligament cross-sectional area becomes smaller thus increasing the bending stress [9] and therefore increasing the stress intensity factors. 
Table 1. List of SIFs of sickle-shaped crack under bending moments.

\begin{tabular}{|c|c|c|c|c|c|c|c|c|}
\hline \multirow{2}{*}{$x / h$} & \multirow{2}{*}{$a / D$} & \multicolumn{7}{|c|}{$a / b$} \\
\hline & & 0.0 & 0.2 & 0.4 & 0.6 & 0.8 & 1.0 & 1.2 \\
\hline \multirow{6}{*}{0.00} & 0.1 & 0.8764 & 0.8440 & 0.8722 & 0.8861 & 0.9143 & 0.9499 & 0.9966 \\
\hline & 0.2 & 0.8270 & 0.8111 & 0.8282 & 0.8754 & 0.9153 & 0.9681 & 1.0497 \\
\hline & 0.3 & 0.8485 & 0.8422 & 0.8725 & 0.9333 & 1.0026 & 1.0956 & 1.2048 \\
\hline & 0.4 & 0.9403 & 0.9545 & 1.0048 & 1.0863 & 1.2035 & 1.3448 & 1.4972 \\
\hline & 0.5 & 1.1364 & 1.1466 & 1.2617 & 1.3977 & 1.5935 & 1.8123 & 2.0353 \\
\hline & 0.6 & 1.5107 & 1.5560 & 1.7312 & 2.0395 & 2.3831 & 2.7430 & 3.0993 \\
\hline \multirow{6}{*}{0.17} & 0.1 & 0.8819 & 0.8515 & 0.8855 & 0.8898 & 0.9150 & 0.9472 & 0.9819 \\
\hline & 0.2 & 0.8319 & 0.8161 & 0.8309 & 0.8768 & 0.9125 & 0.9570 & 1.0223 \\
\hline & 0.3 & 0.8529 & 0.8459 & 0.8726 & 0.9327 & 0.9958 & 1.0759 & 1.1633 \\
\hline & 0.4 & 0.9457 & 0.9576 & 1.0067 & 1.0828 & 1.1898 & 1.3126 & 1.4359 \\
\hline & 0.5 & 1.1419 & 1.1494 & 1.2556 & 1.3890 & 1.5684 & 1.7596 & 1.9412 \\
\hline & 0.6 & 1.5151 & 1.5606 & 1.7269 & 2.0197 & 2.3356 & 2.6511 & 2.9432 \\
\hline \multirow{6}{*}{0.33} & 0.1 & 0.8928 & 0.8658 & 0.8889 & 0.8945 & 0.9113 & 0.9316 & 0.9263 \\
\hline & 0.2 & 0.8451 & 0.8284 & 0.8371 & 0.8765 & 0.8980 & 0.9151 & 0.9270 \\
\hline & 0.3 & 0.8643 & 0.8556 & 0.8733 & 0.9262 & 0.9663 & 1.0046 & 1.0242 \\
\hline & 0.4 & 0.9598 & 0.9661 & 1.0086 & 1.0659 & 1.1377 & 1.2005 & 1.2348 \\
\hline & 0.5 & 1.1569 & 1.1571 & 1.2415 & 1.3530 & 1.4767 & 1.5781 & 1.6361 \\
\hline & 0.6 & 1.5282 & 1.5690 & 1.7069 & 1.9426 & 2.1629 & 2.3334 & 2.4367 \\
\hline \multirow{6}{*}{0.50} & 0.1 & 0.9162 & 0.8797 & 0.9003 & 0.9040 & 0.9070 & 0.9070 & 0.8381 \\
\hline & 0.2 & 0.8702 & 0.8487 & 0.8508 & 0.8780 & 0.8729 & 0.8447 & 0.7783 \\
\hline & 0.3 & 0.8863 & 0.8783 & 0.8864 & 0.9157 & 0.9156 & 0.8859 & 0.8118 \\
\hline & 0.4 & 0.9869 & 0.9890 & 1.0134 & 1.0360 & 1.0471 & 1.0146 & 0.9329 \\
\hline & 0.5 & 1.1853 & 1.1789 & 1.2364 & 1.2884 & 1.3166 & 1.2802 & 1.1840 \\
\hline & 0.6 & 1.5557 & 1.5826 & 1.6731 & 1.8038 & 1.8620 & 1.8178 & 1.6948 \\
\hline \multirow{6}{*}{0.67} & 0.1 & 0.9589 & 0.9138 & 0.9317 & 0.9247 & 0.9037 & 0.8736 & 0.7209 \\
\hline & 0.2 & 0.9179 & 0.8896 & 0.8835 & 0.8870 & 0.8399 & 0.7460 & 0.5889 \\
\hline & 0.3 & 0.9277 & 0.9247 & 0.9209 & 0.9039 & 0.8411 & 0.7197 & 0.5498 \\
\hline & 0.4 & 1.0378 & 1.0366 & 1.0261 & 0.9915 & 0.9108 & 0.7588 & 0.5699 \\
\hline & 0.5 & 1.2358 & 1.2248 & 1.2432 & 1.1854 & 1.0752 & 0.8776 & 0.6536 \\
\hline & 0.6 & 1.6046 & 1.6046 & 1.6182 & 1.5808 & 1.4143 & 1.1340 & 0.8424 \\
\hline \multirow{6}{*}{0.83} & 0.1 & 1.0463 & 1.0252 & 1.0303 & 0.9754 & 0.9162 & 0.8417 & 0.5851 \\
\hline & 0.2 & 1.0284 & 0.9959 & 0.9723 & 0.9234 & 0.8068 & 0.6217 & 0.3750 \\
\hline & 0.3 & 1.0240 & 1.0371 & 1.0056 & 0.9054 & 0.7400 & 0.5050 & 0.2703 \\
\hline & 0.4 & 1.1543 & 1.1475 & 1.0677 & 0.9298 & 0.7115 & 0.4405 & 0.2155 \\
\hline & 0.5 & 1.3404 & 1.3253 & 1.2509 & 1.0199 & 0.7291 & 0.4095 & 0.2280 \\
\hline & 0.6 & 1.6921 & 1.6449 & 1.5162 & 1.2219 & 0.8028 & 0.4318 & 0.4204 \\
\hline
\end{tabular}




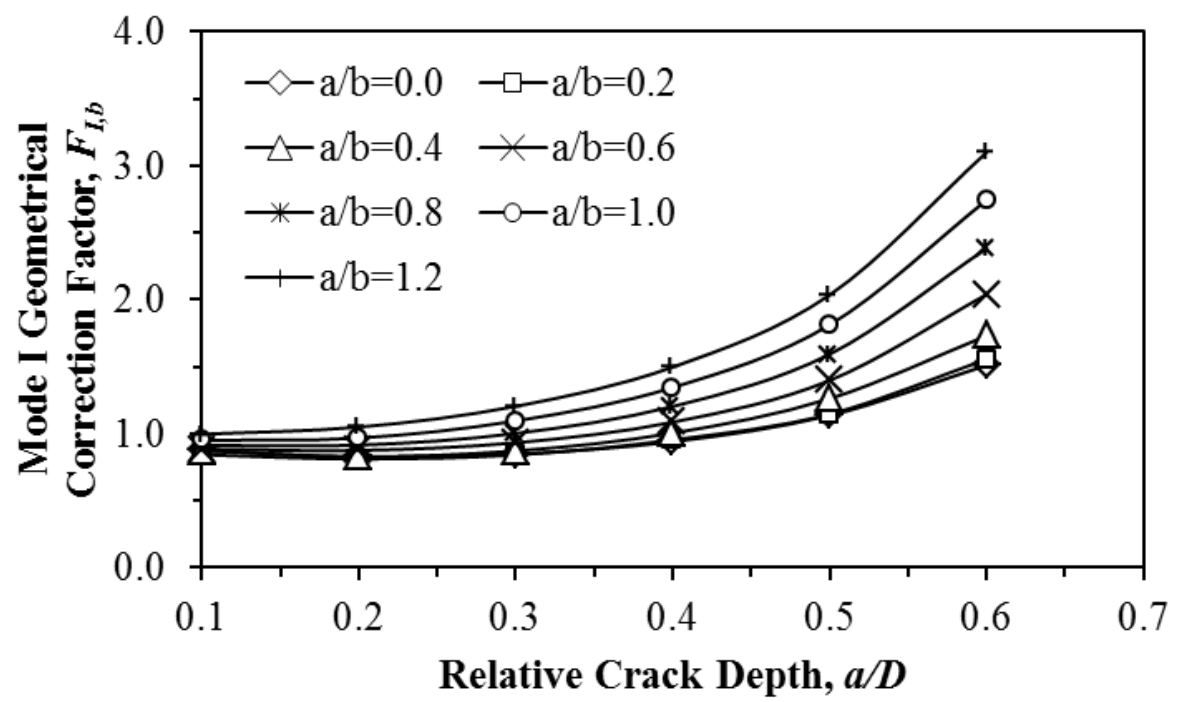

Figure 8 The SIFs for different $a / b$ at the $x / h=0.0$.

\section{CONCLUSIONS}

In this paper, the behaviour of sickle-shaped surface cracks in round bars are investigated and analysed where it is subjected to remote bending moment. The stress intensity factors (SIF) are based on the J-integral. Then the normalized SIFs are plotted against the normalized locations along the crack front. Seven crack aspect ratios, $a / b$ and six relative crack depths, $a / D$ are modelled using ANSYS finite element program. According to the numerical simulations, it is found that:

i). For the shallow cracks $(a / D \leq 0.3)$, the SIFs have no significant difference even though different $a / b$ are used.

ii). For straight or relatively straight cracks $(a / b \leq 0.2)$, the distributions of SIFs along the crack fronts are almost flattened. However when $a / b>0.2$ are used, the SIFs around the outer surfaces are relatively lower that the SIFs closer to the central regions.

iii). From numerical simulations, it is observed that the circumferential side cracks experience insignificant mode I opening mechanisms compared with the cracks located at the upper side.

\section{ACKNOWLEDGEMENTS}

Author acknowledges Universiti Tun Hussein Onn Malaysia for supporting this work.

\section{REFERENCES}

[1] Ali N, Mustapa M, Ghazali M, Sujitno T, Ridha M. Fatigue life prediction of commercially pure titanium after nitrogen ion implantation. International Journal of Automotive and Mechanical Engineering. 2013;7:1005.

[2] Daud R, Ariffin A, Abdullah S. Validation of crack interaction limit model for parallel edge cracks using two-dimensional finite element analysis. International Journal of Automotive and Mechanical Engineering. 2013;7:993. 
[3] Kamal M, Rahman MM. Finite Element-Based Fatigue Behaviour of Springs in Automobile Suspension. International Journal of Automotive and Mechanical Engineering. 2014;10:1910.

[4] Wor L, Rahman MM. Stress behavior of tailor-welded blanks for dissimilar metals using finite element method. International Journal of Automotive and Mechanical Engineering. 2015;11:2541.

[5] Ismail AE, Aziz MCA. Tensile strength of woven yarn kenaf fiber reinforced polyester composites. 2015.

[6] Siswanto WA, Nagentrau M, Tobi M, Latif A. Prediction of residual stress using explicit finite element method. Journal of Mechanical Engineering and Sciences. 2015;9:1556-70.

[7] Ismail AE, Ariffin A, Abdullah S, Ghazali M. Off-set crack propagation analysis under mixed mode loadings. International Journal of Automotive Technology. 2011;12:225-32.

[8] Ismail AE, Ariffin A, Abdullah S, Ghazali M. Stress intensity factors for surface cracks in round bar under single and combined loadings. Meccanica. 2012;47:1141-56.

[9] Toribio J, Álvarez N, González B, Matos J. A critical review of stress intensity factor solutions for surface cracks in round bars subjected to tension loading. Engineering Failure Analysis. 2009;16:794-809.

[10] Carpinteri A, Vantadori S. Sickle-shaped cracks in metallic round bars under cyclic eccentric axial loading. International Journal of Fatigue. 2009;31:759-65.

[11] Mattheck C, Morawietz P, Munz D. Stress intensity factors of sickle-shaped cracks in cylindrical bars. International Journal of Fatigue. 1985;7:45-7.

[12] Hobbs J, Burguete R, Heyes P, Patterson E. A photoelastic analysis of crescentshaped cracks in bolts. The Journal of Strain Analysis for Engineering Design. 2001;36:93-100.

[13] Toribio J, Matos J-C, González B, Escuadra J. Fatigue crack growth in round bars for rock anchorages: the role of residual stresses. Procedia Structural Integrity. 2016;2:2734-41.

[14] Śnieżek L, Ślęzak T, Grzelak K, Hutsaylyuk V. An experimental investigation of propagation the semi-elliptical surface cracks in an austenitic steel. International Journal of Pressure Vessels and Piping. 2016;144:35-44.

[15] Coules H. Stress intensity interaction between dissimilar semi-elliptical surface cracks. International Journal of Pressure Vessels and Piping. 2016;146:55-64.

[16] Weißgraeber P, Felger J, Geipel D, Becker W. Cracks at elliptical holes: stress intensity factor and finite fracture mechanics solution. European Journal of Mechanics-A/Solids. 2016;55:192-8.

[17] Zerbst U, Vormwald M, Pippan R, Gänser H-P, Sarrazin-Baudoux C, Madia M. About the fatigue crack propagation threshold of metals as a design criterion-a review. Engineering Fracture Mechanics. 2016;153:190-243.

[18] Kamal M, Rahman MM. An Integrated Approach for fatigue life estimation based on continuum mechanics theory and genetic algorithm. International Journal of Automotive and Mechanical Engineering. 2015;11:2756-70.

[19] Kamal M, Rahman MM. Fatigue life estimation based on continuum mechanics theory with application of genetic algorithm. International Journal of Automotive and Mechanical Engineering. 2015;11:2686-98. 
[20] Yunoh MFM, Abdullah S, Saad MHM, Nopiah ZM, Nuawi MZ. Fatigue feature extraction analysis based on a K-means clustering approach. Journal of Mechanical Engineering and Sciences. 2015;8:1275-82.

[21] Ahmad MIM, Arifin A, Abdullah S. Evaluation of magnetic flux leakage signals on fatigue crack growth of mild steel. Journal of Mechanical Engineering and Sciences. 2015;9:1727-33.

[22] Abdul Majid MS, Daud R, Afendi M, Amin NAM, Cheng EM, Gibson AG, et al. Stress-Strain response modelling of glass fibre reinforced epoxy composite pipes under multiaxial loadings. Journal of Mechanical Engineering and Sciences. 2014;6:916-28.

[23] Kamal M, Rahman MM. Dual-Criteria method for determining critical plane orientation for multiaxial fatigue prediction using a genetic algorithm. International Journal of Automotive and Mechanical Engineering. 2015;11:2571-81.

[24] Kamal M, Rahman MM. Finite element-based fatigue behaviour of springs in automobile suspension. International Journal of Automotive and Mechanical Engineering. 2014;10:1910-9.

[25] Daud R, Ariffin AK, Abdullah S. Validation of Crack Interaction Limit Model for Parallel Edge Cracks using Two-Dimensional Finite Element Analysis. International Journal of Automotive and Mechanical Engineering. 2013;7:9931004.

[26] Predan J, Močilnik V, Gubeljak N. Stress intensity factors for circumferential semi-elliptical surface cracks in a hollow cylinder subjected to pure torsion. Engineering Fracture Mechanics. 2013;105:152-68.

[27] Carpinteri A, Brighenti R, Vantadori S, Viappiani D. Sickle-shaped crack in a round bar under complex Mode I loading. Fatigue \& Fracture of Engineering Materials \& Structures. 2007;30:524-34.

[28] Carpinteri A, Vantadori S. Sickle-shaped surface crack in a notched round bar under cyclic tension and bending. Fatigue \& Fracture of Engineering Materials \& Structures. 2009;32:223-32.

[29] Ismail A, Ariffin A, Abdullah S, Ghazali M. Stress intensity factors under combined tension and torsion loadings. Indian Journal of Engineering \& Materials Sciences. 2012;19:5-16.

[30] Ariffin AK, Abdullah S, Ghazali MJ, Abdulrazzaq M, Daud R. Stress intensity factors under combined bending and torsion moments. Journal of Zhejiang University Science A. 2012;13:1-8.

[31] Rice JR. A path independent integral and the approximate analysis of strain concentration by notches and cracks. Journal of Applied Mechanics. 1968;35:379-86.

[32] Parks D. The virtual crack extension method for nonlinear material behavior. Computer Methods in Applied Mechanics and Engineering. 1977;12:353-64.

[33] Rahman S. Probabilistic fracture mechanics: J-estimation and finite element methods. Engineering Fracture Mechanics. 2001;68:107-25.

[34] Yang F, Kuang Z, Shlyannikov V. Fatigue crack growth for straight-fronted edge crack in a round bar. International Journal of Fatigue. 2006;28:431-7.

[35] Bovsunovsky A. Energy dissipation in the non-propagating surface cracks in steel round bar at torsional vibration. Engineering Fracture Mechanics. 2012;92:32-9. 